\title{
Reflexiones y esperanzas sobre la necesidad de una reforma de la medicina legal y forense en España
}

Yo conocí y empecé a trabajar en ella, en la década de 1960, una Medicina Legal y Forense organizada en dos vías, del servicio en la Administración de Justicia y de la enseñanza e investigación, que en muchos profesionales confluían y se complementaban. Mucho más tarde, quien había elegido también la carrera universitaria tuvo que renunciar a ser médico forense si quería ser profesor universitario, funcionario, o viceversa. Desde entonces, para que sea compatible el ejercicio médico forense con la docencia universitaria tiene que ser como profesor asociado, en unas condiciones que en muchas universidades se han ido convirtiendo en precarias, humillantes y solo soportables por lo honroso y admirable de la tarea, no por la dignidad de las condiciones de los contratos a que deben acogerse estos profesores asociados de Medicina Legal.

También conocí una época en la que el médico forense podía realizar informes periciales privados, cotejando sus conocimientos con los de otros expertos.

Era un tiempo en el que valía la pena preparar los larguísimos programas de las oposiciones para médico forense, porque el opositor lo hacía a plazas en todo el Estado Español, con lo que la tarea, que no era nada fácil, tampoco era imposible, máxime porque había oposiciones que tenían cometidos y programas muy próximos, como eran las de médico forense y las de médicos de la Inspección de Servicios Sanitarios de la Seguridad Social, que tenían muchos temas comunes tanto de Derecho médico y sanitario como de accidentes de trabajo y enfermedades profesionales, valoración de incapacidades laborales y daño corporal, y organización y gestión de la asistencia médico-sanitaria.

Es cierto que ese sistema tenía serios defectos estructurales, ya que consistía en distintas vías o salidas profesionales que, pudiendo confluir, estaban pensadas como independientes entre sí, de modo que eran los propios profesionales los que organizaban su modelo de vida profesional.
Con el advenimiento de la democracia en España se producen cambios legislativos; en 1986, la integración en la Unión Europea; y en el año 2000, la moneda única, el euro. Desgraciadamente, a criterio de quien escribe, estos cambios no llevaron consigo la modernización ni reforma de la Medicina Legal y Forense que en España era necesaria para equipararse a la organización que esta tenía en el resto de la Unión Europea. Es más, las reformas del sistema anterior, que he sintetizado al principio, acentuaron la compartimentación de los sistemas existentes: el de la Medicina Forense del Ministerio de Justicia, con los Institutos de Medicina Legal y las tres secciones del Instituto Nacional de Toxicología; el de la docencia universitaria con la multiplicación y la fragmentación de cátedras, muchas veces convertidas en pequeñas unidades docentes de departamentos cada vez más multiformes; y las tareas médico-legales del Cuerpo Nacional de Policía y de la Guardia Civil, de la Medicina Social y del Trabajo, que con la fragmentación de España en las 17 comunidades autónomas (más las dos ciudades autónomas de Ceuta y Melilla) creo que llevó al deterioro funcional.

Todo ello está sin duda relacionado con la aprobaciónpor el Consejo de Ministros, el 16 de mayo de 2014, del Real Decreto por el que se crea y regula el Consejo Médico Forense, cuya necesidad aparecía recogida en 1988 en el Libro Blanco de la Medicina Forense, publicado por el Ministerio de Justicia.

El Consejo Médico Forense se constituye como un órgano consultivo y de asesoramiento científico-técnico en materia de Medicina Legal y Ciencias Forenses, que no es un órgano pericial sino de coordinación, formación y máxima garantía de la Medicina Forense y Legal en todo el Estado Español, para lo cual podrá mantener relaciones con otros organismos nacionales o internacionales en cuanto interese a la actividad médico-forense. Esta iniciativa nos parece no solo oportuna sino también necesaria, y nos da pie para plantear las reflexiones siguientes.

\section{A. Piga Rivero}

Profesor Emérito de la Universidad de Alcalá (Madrid).

Cargos desempeñados entre otros:

Funcionario de las Naciones Unidas (Organización Mundial de la Salud).

Presidente del Comité de Problemas Jurídicos en el campo de la Medicina. Consejo de Europa.

Miembro del Comité de Expertos sobre la armonización de las normas de autopsia del Consejo de Europa, a propuesta de la Organización Mundial de la Salud.

Correspondencia: Antonio Piga Rivero Facultad de Medicina. Universidad de Alcalá Ctra. Madrid-Barcelona $\mathrm{Km} 33.600$ 28871 Alcalá de Henares. Madrid

E-mail: antonio.piga@uah.es 
Me gustaría equivocarme, pero creo que al igual que la estructura en comunidades autónomas ha fragmentado, desunido y dividido en compartimentos lo que antaño eran cuerpos, normas y recursos nacionales, las grandes tareas de la Medicina Legal (forense, universitaria, criminalística policial y médico-social) se han separado aún más que antes. Ni siquiera se aprovecha el estímulo que la Unión Europea, el Consejo de Europa y organizaciones internacionales como INTERPOL dan a la mayor integración con la criminología y la criminalística de la Policía y la Guardia Civil. En España observamos que las tareas de colaboración, e incluso de gran importancia científica, se realizan más bien por iniciativas individuales que por estímulos institucionales generalizados en todo el Estado.

Invade la tristeza cuando nuestros antiguos alumnos nos cuentan sus problemas, que incluyen el hecho (que creemos escandaloso) de que la especialidad en Medicina Legal y Forense no suponga ninguna ventaja a la hora de trabajar en ese campo frente a quienes no la tienen; cuando nos dicen que ahora la oposición para médico forense está absurdamente fragmentada en comunidades autónomas que uno debe elegir de antemano; que apenas se convocan oposiciones, y que estas tareas se practican por interinos, a veces "eternos".

También nos entristece ver cómo nuestra querida universidad trata a los profesores asociados de Medicina Legal con contratos de pocos meses de duración que, parados otros meses, hay que volver a firmar. Con esto, que sucede también en la Universidad de Alcalá, resulta evidente que la institución universitaria está básicamente interesada en equilibrar su presupuesto tras años de mala administración, y en cumplir los requisitos de la Unión Europea, nacionales y autonómicos, para expender los títulos, convirtiendo la autonomía universitaria en una excusa para culpabilizar a los propios profesores por no conseguir proyectos con financiación y publicaciones de impacto. Así, la mutuamente enriquecedora relación entre práctica médico-forense judicial y actividad docente e investigadora de la universidad se convierte en una interacción que ha de llevarse a cabo con un creciente sacrificio personal.

En España llevamos ya sufriendo 6 u 8 años una gravísima crisis social y económica, que muchos pensamos que solo se superará tras haber realizado grandes cambios. En esta situación, la gran pregunta es la siguiente: ¿debemos, quienes estamos dedicados a la Medicina Legal y Forense, adoptar una actitud de ir cumpliendo, como hasta ahora, lo mejor posible nuestro deber y esperar que las autoridades administrativamente competentes vayan tratando de mejorar la organización de los servicios? ¿O deberíamos utilizar la actual crisis para promover en todo el Estado Español una gran reflexión y tratar de convencer a las máximas autoridades de Justicia, Educación, Ciencia, Sanidad y Seguridad de la Nación Española para lo que se podría aprovechar la oportunidad que ofrece la creación por el Ministerio de Justicia del Consejo Médico-Forense?

Bien sé que mucho antes que yo otros han clamado y claman por esta tan necesaria reforma, que recogía de forma documentada en su discurso de ingreso en la Real Academia Nacional de Medicina la catedrática de Medicina Legal Profesora María Castellano. Igualmente ha tratado este tema, en numerosos escritos, el catedrático Profesor Enrique Villanueva. Sin embargo, la recentísima creación del Consejo Médico-Forense constituye una iniciativa que es de esperar será muy beneficiosa para la Medicina Forense española. Ahora bien, cuanto mayores puedan ser las miras y razonables las ambiciones, mayores pueden ser las expectativas. Por ello me atrevo a aprovechar esta ocasión para incitar a afrontar reformas de la Medicina Forense y Legal que no se queden, como en otras ocasiones, demasiado cortas en sus ambiciones. 